\title{
On Strong Form of Irresolute Functions
}

\author{
M.Lellis Thivagar \\ School Of Mathematics, \\ Madurai Kamaraj University, \\ Madurai-625021. \\ Tamilnadu,INDIA.
}

\author{
C.Santhini \\ V.V.Vanniaperumal College For Women, \\ Virudhunagar-626001. \\ Tamilnadu,INDIA.
}

\begin{abstract}
A strong form of $\Lambda_{a}$-irresolute function called completely $\Lambda_{a}$-irresolute function is introduced and several characterizations of such functions are investigated. The relationships among completely $\Lambda_{a}$-irresolute functions, separation axioms and covering properties are also investigated.
\end{abstract}

\section{Keywords}

$\Lambda_{a}$-closed sets, $\Lambda_{a}$-open sets, completely $\Lambda_{a}$-irresolute functions, $\Lambda_{a}$-compact spaces, $\Lambda_{a}$-connected spaces and $\Lambda_{a}$-normal spaces.

\section{INTRODUCTION}

In 1972, Crossley and Hildebrand [2] introduced the notion of irresoluteness. Various types of irresolute functions have been introduced over the course of years. Recently Thivagar et al.[5],introduced a new class of sets called $\Lambda_{a}$-sets via aclosed sets and investigated several properties of such sets. The purpose of this paper is to introduce a new form of irresolute function called completely $\Lambda_{a}$-irresolute function which is stronger than $\Lambda_{a}$-irresolute functions. We also investigate the relationships among completely $\Lambda_{a}$ irresolute functions, separation axioms and covering properties.

\section{PRELIMINARIES}

Throughout the paper $(\mathrm{X}, \tau)$ and $(\mathrm{Y}, \sigma)$ and $(\mathrm{Z}, \eta)$ (or simply $\mathrm{X}, \mathrm{Y}$ and $\mathrm{Z}$ ) represent topological spaces on which no separation axioms are assumed. For a subset $\mathrm{A}$ of $\mathrm{X}, \operatorname{cl}(\mathrm{A})$, $\operatorname{int}(\mathrm{A})$ and $\mathrm{A}^{\mathrm{c}}$ denote the closure of $\mathrm{A}$, interior of $\mathrm{A}$ and the complement of A respectively. A subset A of a topological space $\mathrm{X}$ is called $\delta$-closed if $\mathrm{A}=\mathrm{cl}_{\delta}(\mathrm{A})$ where $\mathrm{cl}_{\delta}(\mathrm{A})=$ $\{\mathrm{x} \in \mathrm{X} \quad$ : int $(\mathrm{cl}(\mathrm{U})) \cap \mathrm{A} \neq \phi, \mathrm{U} \in \tau$ and $\mathrm{x} \in \mathrm{U}\}$. The complement of $\delta$ - closed set is called $\delta$-open set. A subset A of a topological space $\mathrm{X}$ is called regular open if $\mathrm{A}$ $=$ int $(\operatorname{cl}(\mathrm{A}))$. The complement of regular open set is called regular closed set. A subset $A$ of a topological space $\mathrm{X}$ is called an a-open set [3] if $\mathrm{A} \subset \operatorname{int}\left(\mathrm{cl}\left(\operatorname{int}_{\delta}(\mathrm{A})\right)\right)$. The complement of an a-open set is called an a-closed set. A subset A of a topological space $\mathrm{X}$ is called a $\delta$-semiopen [7] if $\mathrm{A} \subset \mathrm{cl}$ (int $\delta$ (A)). The complement of a $\delta$-semiopen set is called a $\delta$-semiclosed set.

Definition 2.1. A subset $A$ of a topological space $(\mathrm{X}, \tau)$ is said to be a $\Lambda_{a}$-set [5] if $\Lambda_{a}(\mathrm{~A})=\mathrm{A}$ where $\Lambda_{a}(\mathrm{~A})=$ $\cap\{\mathrm{O} \in \mathrm{aO}(\mathrm{X}, \tau): \mathrm{A} \subset \mathrm{O}\}$.

Definition 2.2. A subset $\mathrm{A}$ of a topological space $(\mathrm{X}, \tau)$ is said to be $\Lambda_{a}$-closed [5] if $\mathrm{A}=\mathrm{T} \cap \mathrm{C}$ where $\mathrm{T}$ is a $\Lambda_{a}$ set and $\mathrm{C}$ is an a-closed set. A is said to be $\Lambda_{a}$-open if $\mathrm{X}-\mathrm{A}$ is $\Lambda_{a}$ - closed.

Definition 2.3. A function $\mathrm{f}:(\mathrm{X}, \tau) \rightarrow(\mathrm{Y}, \sigma)$ is called (i) strongly continuous [4] if $f^{-1}(V)$ is clopen in $X$ for every subset $\mathrm{V}$ in $\mathrm{Y}$.

(ii) completely continuous [8] if $\mathrm{f}^{-1}(\mathrm{~V})$ is regular open in $\mathrm{X}$ for every open set $\mathrm{V}$ in $\mathrm{Y}$.

(iii) almost a-continuous [3] if $\mathrm{f}^{-1}(\mathrm{~V})$ is a-open in $\mathrm{X}$ for every regular open set $\mathrm{V}$ in $\mathrm{Y}$.

(iv) $\Lambda_{a}$-continuous [5] if $\mathrm{f}^{-1}(\mathrm{~V})$ is $\Lambda_{a}$-open in $\mathrm{X}$ for every open set V in Y.

(v) $\Lambda_{a}$-irresolute [5] if $\mathrm{f}^{-1}(\mathrm{~V})$ is $\Lambda_{a}$-open in $\mathrm{X}$ for every $\Lambda_{a}$-open set $\mathrm{V}$ in $\mathrm{Y}$.

(vi) quasi $\Lambda_{a}$-irresolute [5] if $\mathrm{f}^{-1}(\mathrm{~V})$ is $\Lambda_{a}$-open in $\mathrm{X}$ for every a-open set $\mathrm{V}$ in $\mathrm{Y}$.

(vii) completely $\alpha$-irresolute [10] if $\mathrm{f}^{-1}(\mathrm{~V})$ is regular open in $\mathrm{X}$ for every $\alpha$-open set $\mathrm{V}$ in $\mathrm{Y}$.

(viii) completely $\delta$-semi-irresolute [8] if $\mathrm{f}^{-1}(\mathrm{~V})$ is regular open in X for every $\delta$-semiopen set $\mathrm{V}$ in Y.

(ix)R-map [8] if $\mathrm{f}^{-1}(\mathrm{~V})$ is regular open in $\mathrm{X}$ for every regular open set $\mathrm{V}$ in $\mathrm{Y}$.

(x) a-irresolute [3] if $\mathrm{f}^{-1}(\mathrm{~V})$ is a-open in $\mathrm{X}$ for every a-open set $\mathrm{V}$ in $\mathrm{Y}$.

(xii) $a^{*}$-closed [3] if $\mathrm{f}(\mathrm{V})$ is a-closed in $\mathrm{X}$ for every a-closed set $\mathrm{V}$ in $\mathrm{Y}$. 


\section{COMPLETELY $\Lambda_{a}$-IRRESOLUTE FUNCTIONS}

In this section we introduce completely $\Lambda_{a}$-irresolute functions and obtain several properties concerning such functions.

Definition 3.1. A function $\mathrm{f}:(\mathrm{X}, \tau) \rightarrow(\mathrm{Y}, \sigma)$ is said to be completely $\Lambda_{a}$-irresolute function if the inverse image of every $\Lambda_{a}$-open subset of $\mathrm{Y}$ is regular open in $\mathrm{X}$.

Example3.2. Let $\mathrm{X}=\{\mathrm{a}, \mathrm{b}, \mathrm{c}, \mathrm{d}\}=\mathrm{Y}, \tau=\{\phi,\{\mathrm{a}\},\{\mathrm{b}\},\{\mathrm{a}, \mathrm{b}\}$, $\{\mathrm{c}, \mathrm{d}\},\{\mathrm{a}, \mathrm{c}, \mathrm{d}\},\{\mathrm{b}, \mathrm{c}, \mathrm{d}\}, X\}$ and $\sigma=\{\phi,\{\mathrm{a}\},\{\mathrm{c}\},\{\mathrm{a}, \mathrm{b}\},\{\mathrm{a}, \mathrm{c}\}$, $\{\mathrm{a}, \mathrm{b}, \mathrm{c}\},\{\mathrm{a}, \mathrm{c}, \mathrm{d}\}, \mathrm{Y}\}$. Define a function $\mathrm{f}:(\mathrm{X}, \tau) \rightarrow(\mathrm{Y}, \sigma)$ by $\mathrm{f}(\mathrm{a})=\mathrm{d}, \mathrm{f}(\mathrm{b})=\mathrm{c}, \mathrm{f}(\mathrm{c})=\mathrm{a}$ and $\mathrm{f}(\mathrm{d})=\mathrm{b}$. Then $\mathrm{f}$ is completely $\Lambda_{a}$-irresolute.

Theorem 3.3 The following are equivalent for a function $\mathrm{f}:(\mathrm{X}, \tau) \rightarrow(\mathrm{Y}, \sigma)$

(i) f is completely $\Lambda_{a}$-irresolute.

(ii) the inverse image of every $\Lambda_{a}$-closed subset of $\mathrm{Y}$ is regular closed in $\mathrm{X}$.

Proof: (i) $\Rightarrow$ (ii) Suppose f is completely $\Lambda_{a}$-irresolute. Let $\mathrm{V}$ be a $\Lambda_{a}$-closed subset of $\mathrm{Y}$.Then $\mathrm{Y}-\mathrm{V}$ is $\Lambda_{a}$-open in $\mathrm{Y}$. By (i), $\mathrm{f}^{-1}(\mathrm{Y}-\mathrm{V})=\mathrm{X}-\mathrm{f}^{-1}(\mathrm{~V})$ is regular open in $\mathrm{X}$ which implies $f^{-1}(V)$ is regular closed in $X$. Thus (ii) holds.

Similarly (ii) $\Rightarrow$ (i) holds.

Remark 3.4.It is clear that every strongly continuous function is completely $\Lambda_{a}$-irresolute. However the converse is not true as shown by the following example.

Example 3.5. Let $X$ and $\tau$ be same as in example 3.2.Then $\mathrm{f}$ is completely $\Lambda_{a}$-irresolute but not strongly continuous since $\mathrm{f}^{-1}\{\mathrm{~b}\}=\{\mathrm{d}\}$ is not clopen in $\mathrm{X}$.

Theorem 3.6.Every completely $\Lambda_{a}$-irresolute function is

(i) $\Lambda_{a}$-irresolute.

(ii) a-irresolute.

(iii) quasi- $\Lambda_{a}$-irresolute.

(iv) a R-map.

(v) almost a-continuous.

\section{Proof :}

(i) Let $\mathrm{f}:(\mathrm{X}, \tau) \rightarrow(\mathrm{Y}, \sigma)$ be a completely $\Lambda_{a}$-irresolute function and $\mathrm{V}$ be $\Lambda_{a}$-open in Y. Since f is completely $\Lambda_{a}{ }^{-}$ irresolute, $\mathrm{f}^{-1}(\mathrm{~V})$ is regular open in $\mathrm{X}$. Since every regular open set is a-open [7], $\mathrm{f}^{-1}(\mathrm{~V})$ is a-open in $\mathrm{X}$. By proposition 4.20[5],

$\mathrm{f}^{-1}(\mathrm{~V})$ is $\Lambda_{a}$-open in $\mathrm{X}$ which implies $\mathrm{f}$ is $\Lambda_{a}$-irresolute.

(ii) Let $\mathrm{f}:(\mathrm{X}, \tau) \rightarrow(\mathrm{Y}, \sigma)$ be a completely $\Lambda_{a}$-irresolute function and $\mathrm{V}$ be an a-open in $\mathrm{Y}$. By proposition 4.20[5], $\mathrm{V}$ is $\Lambda_{a}$-open in $\mathrm{Y}$. Since $\mathrm{f}$ is completely $\Lambda_{a}$-irresolute, $\mathrm{f}^{-1}(\mathrm{~V})$ is regular open in X. Since every regular open set is a-open [7], $\mathrm{f}^{-1}(\mathrm{~V})$ is a-open in $\mathrm{X}$ which implies $\mathrm{f}$ is a - irresolute.

(iii) Let $\mathrm{f}:(\mathrm{X}, \tau) \rightarrow(\mathrm{Y}, \sigma)$ be a completely $\Lambda_{a}$-irresolute function and $\mathrm{V}$ be an a-open in $\mathrm{Y}$. By proposition 4.20[5], $\mathrm{V}$ is $\Lambda_{a}$-open in $\mathrm{Y}$. Since $\mathrm{f}$ is completely $\Lambda_{a}$-irresolute, $\mathrm{f}^{-1}(\mathrm{~V})$ is regular open in X. Since every regular open set is a-open [7],

$\mathrm{f}^{-1}(\mathrm{~V})$ is a-open in $\mathrm{X}$. By proposition $4.20[5], \mathrm{f}^{-1}(\mathrm{~V})$ is $\Lambda_{a^{-}}$ open in $\mathrm{X}$ which implies $\mathrm{f}$ is quasi $\Lambda_{a}$-irresolute.

(iv) Let $\mathrm{f}:(\mathrm{X}, \tau) \rightarrow(\mathrm{Y}, \sigma)$ be a completely $\Lambda_{a}$-irresolute function and $\mathrm{V}$ be a regular open set in $\mathrm{Y}$. Since every regular open set is a-open [7], $\mathrm{V}$ is a-open in Y. By proposition 4.20[5], $\mathrm{V}$ is $\Lambda_{a}$-open in $\mathrm{Y}$. Since $\mathrm{f}$ is completely $\Lambda_{a}$-irresolute, $\mathrm{f}^{-1}(\mathrm{~V})$ is regular open in $\mathrm{X}$ which implies $\mathrm{f}$ is a $\mathrm{R}$-map.

(v) Let $\mathrm{f}:(\mathrm{X}, \tau) \rightarrow(\mathrm{Y}, \sigma)$ be a completely $\Lambda_{a}$-irresolute function and $\mathrm{V}$ be a regular open set in $\mathrm{Y}$. Since every regular open set is a-open [7], $\mathrm{V}$ is a-open in Y. By proposition 4.20[5], $\mathrm{V}$ is $\Lambda_{a}$-open in Y. Since $\mathrm{f}$ is completely $\Lambda_{a}$-irresolute,

$\mathrm{f}^{-1}(\mathrm{~V})$ is regular open in $\mathrm{X}$ which implies $\mathrm{f}^{-1}(\mathrm{~V})$ is a-open in $\mathrm{X}$ and hence $\mathrm{f}$ is almost a-continuous.

Remark 3.7. The converses of the above theorem are not true as shown by the following examples.

Example 3.8.Let $X=\{a, b, c, d\}=Y, \tau=\{\phi,\{a\},\{c\},\{a, b\}$, $\{a, c\},\{a, b, c\},\{a, b, d\}, X\}$ and $\sigma=\{\phi,\{a\},\{b, c\},\{a, b, c\}, Y\}$.

Define a function $\mathrm{f}:(\mathrm{X}, \tau) \rightarrow(\mathrm{Y}, \sigma)$ by $\mathrm{f}(\mathrm{a})=\mathrm{b}, \mathrm{f}(\mathrm{b})=\mathrm{c}$, $\mathrm{f}(\mathrm{c})=\mathrm{a}$ and $\mathrm{f}(\mathrm{d})=\mathrm{d}$. Then $\mathrm{f}$ is a-irresolute and R-map but not completely $\Lambda_{a}$-irresolute since $\mathrm{f}^{-1}(\{\mathrm{a}, \mathrm{d}\})=\{\mathrm{c}, \mathrm{d}\}$ is not regular open in $\mathrm{X}$ where $\{\mathrm{a}, \mathrm{d}\}$ is $\Lambda_{a}$-open in $\mathrm{Y}$.

Example 3.9. Le $X=\{a, b, c, d\}=Y, \tau=\{\phi,\{a\},\{c\},\{d\}$, $\{\mathrm{a}, \mathrm{c}\},\{\mathrm{a}, \mathrm{d}\},\{\mathrm{c}, \mathrm{d}\},\{\mathrm{a}, \mathrm{c}, \mathrm{d}\}, \mathrm{X}\}$ and $\sigma=\{\phi,\{\mathrm{c}\},\{\mathrm{a}, \mathrm{b}\},\{\mathrm{a}, \mathrm{b}, \mathrm{c}\}$, $\{\mathrm{a}, \mathrm{b}, \mathrm{d}\}, \mathrm{Y}\}$.Define a function $\mathrm{f}:(\mathrm{X}, \tau) \rightarrow(\mathrm{Y}, \sigma)$ by $\mathrm{f}(\mathrm{a})=\mathrm{c}$, $\mathrm{f}(\mathrm{b})=\mathrm{d}, \mathrm{f}(\mathrm{c})=\mathrm{b}$ and $\mathrm{f}(\mathrm{d})=\mathrm{a}$. Then $\mathrm{f}$ is $\Lambda_{a}$-irresolute and almost a- continuous but not completely $\Lambda_{a}$-irresolute since $\mathrm{f}^{-1}(\{\mathrm{a}, \mathrm{b}, \mathrm{d}\})=\{\mathrm{b}, \mathrm{c}, \mathrm{d}\}$ is not regular open in $\mathrm{X}$ where $\{\mathrm{a}, \mathrm{b}, \mathrm{d}\}$ is $\Lambda_{a}$-open in Y. 
Example3.10Let $X=\{a, b, c, d\}=Y, \tau=\{\phi,\{a\},\{b\},\{a, b\}$, $\mathrm{X}\}$ and $\sigma=\{\phi,\{\mathrm{a}\},\{\mathrm{b}, \mathrm{c}\},\{\mathrm{a}, \mathrm{b}, \mathrm{c}\}, \mathrm{Y}\}$. Define a function $\mathrm{f}$ : $(\mathrm{X}, \tau) \rightarrow(\mathrm{Y}, \sigma)$ by $\mathrm{f}(\mathrm{a})=\mathrm{c}, \mathrm{f}(\mathrm{b})=\mathrm{d}, \mathrm{f}(\mathrm{c})=\mathrm{a}$ and $\mathrm{f}(\mathrm{d})=\mathrm{b}$. Then $\mathrm{f}$ is quasi- $\Lambda_{a}$-irresolute but not completely $\Lambda_{a}$ irresolute since $\mathrm{f}^{-1}(\{\mathrm{a}, \mathrm{d}\})=\{\mathrm{b}, \mathrm{c}\}$ is not regular open in $\mathrm{X}$ where $\{\mathrm{a}, \mathrm{d}\}$ is $\Lambda_{a}$-open in $\mathrm{Y}$.

Definition 3.11 A space $(X, \tau)$ is said to be $\Lambda_{a}$-space [5] if every $\Lambda_{a}$-closed subset of $X$ is a-closed in $X$.

Theorem 3.12 Let $\mathrm{f}:(\mathrm{X}, \tau) \rightarrow(\mathrm{Y}, \sigma)$ be a completely $\delta$-semi-irresolute function where $\mathrm{Y}$ is a $\Lambda_{a}$-space, then $\mathrm{f}$ is completely $\Lambda_{a}$-irresolute.

Proof : Let V be a $\Lambda_{a}$-closed subset of Y. Since $\mathrm{Y}$ is a $\Lambda_{a}$-space, $\mathrm{V}$ is a-closed in Y. Since every a-closed set is $\delta$ semiclosed [7], $\mathrm{V}$ is $\delta$-semiclosed in Y. Now $\mathrm{f}$ is completely $\delta$-semi-irresolute implies $\mathrm{f}^{-1}(\mathrm{~V})$ is regular closed in $\mathrm{X}$ and so $\mathrm{f}$ is completely $\Lambda_{a}$-irresolute.

Theorem 3.13 Let $\mathrm{f}:(\mathrm{X}, \tau) \rightarrow(\mathrm{Y}, \sigma)$ be a completely $\alpha$-irresolute function where $\mathrm{Y}$ is a $\Lambda_{a}$-space ,then $\mathrm{f}$ is completely $\Lambda_{a}$-irresolute.

Proof : Let V be a $\Lambda_{a}$-closed subset of $\mathrm{Y}$. Since $\mathrm{Y}$ is a $\Lambda_{a}$-space, $\mathrm{V}$ is a-closed in Y. Since every a-closed set is $\alpha$ closed [7], $\mathrm{V}$ is $\alpha$-closed in Y. Now f is completely $\alpha$ irresolute implies $\mathrm{f}^{-1}(\mathrm{~V})$ is regular closed in $\mathrm{X}$ and so $\mathrm{f}$ is completely $\Lambda_{a}$-irresolute.

Theorem 3.14 Let $\mathrm{f}:(\mathrm{X}, \tau) \rightarrow(\mathrm{Y}, \sigma)$ and $\mathrm{g}:(\mathrm{Y}, \sigma)$ $\rightarrow(\mathrm{Z}, \eta)$ be functions. Then the following properties hold:

(i) If $\mathrm{f}$ is completely $\Lambda_{a}$-irresolute and $\mathrm{g}$ is $\Lambda_{a}$-continuous, then $\mathrm{g} \circ \mathrm{f}$ is completely continuous.

(ii) If $\mathrm{f}$ is completely $\Lambda_{a}$-irresolute and $\mathrm{g}$ is $\Lambda_{a}$-irresolute, then $\mathrm{g} \circ \mathrm{f}$ is completely $\Lambda_{a}$-irresolute.

(iii) If $\mathrm{f}$ is almost a-continuous and $\mathrm{g}$ is completely $\Lambda_{a}$ irresolute, then $\mathrm{g} \circ \mathrm{f}$ is $\Lambda_{a}$-irresolute.

(iv) If $\mathrm{f}$ is completely continuous and $\mathrm{g}$ is completely $\Lambda_{a}$ irresolute, then $\mathrm{g} \circ \mathrm{f}$ is completely $\Lambda_{a}$-irresolute.

(v) If $\mathrm{f}$ is a R-map and $\mathrm{g}$ is completely $\Lambda_{a}$-irresolute, then $\mathrm{g} \circ \mathrm{f}$ is completely $\Lambda_{a}$-irresolute.

(vi) If $\mathrm{f}$ is completely $\Lambda_{a}$-irresolute and $\mathrm{g}$ is a $\mathrm{R}$-map, then $\mathrm{g} \circ \mathrm{f}$ is almost a-continuous. (vii) If $\mathrm{f}$ is almost a-continuous and $\mathrm{g}$ is completely $\Lambda_{a}$ irresolute, then $\mathrm{g} \circ \mathrm{f}$ is a-irresolute.

Proof. (i) Let $\mathrm{V}$ be an open set in Z. Since $\mathrm{g}$ is $\Lambda_{a}$ continuous, $\mathrm{g}^{-1}(\mathrm{~V})$ is $\Lambda_{a}$-open in Y. Since $\mathrm{f}$ is completely $\Lambda_{a}$-irresolute, $\mathrm{f}^{-1}\left(\mathrm{~g}^{-1}(\mathrm{~V})\right)=(\mathrm{g} \circ \mathrm{f})^{-1}(\mathrm{~V})$ is regular open in $\mathrm{X}$ and hence $\mathrm{g} \circ \mathrm{f}$ is completely continuous.

Proofs of (ii) - (vii) can be obtained similarly.

Theorem 3.15 If $\mathrm{f}:(\mathrm{X}, \tau) \rightarrow(\mathrm{Y}, \sigma)$ is a surjective, $\mathrm{a}^{*}$-closed function and $\mathrm{g}:(\mathrm{Y}, \sigma) \rightarrow(\mathrm{Z}, \eta)$ is a function such that $\mathrm{g} \circ \mathrm{f}:(\mathrm{X}, \tau) \rightarrow(\mathrm{Z}, \eta)$ is completely $\Lambda_{a}$ irresolute, then $\mathrm{g}$ is $\Lambda_{a}$-irresolute.

Proof. Let V be a $\Lambda_{a}$-closed set in Z. Since $\mathrm{g} \circ \mathrm{f}$ is completely $\Lambda_{a}$-irresolute, $(\mathrm{g} \circ \mathrm{f})^{-1}(\mathrm{~V})=\mathrm{f}^{-1}\left(\mathrm{~g}^{-1}(\mathrm{~V})\right)$ is regular closed in $\mathrm{X}$. Since every regular closed set is a-closed [7], $\mathrm{f}^{-1}\left(\mathrm{~g}^{-1}(\mathrm{~V})\right)$ is a-closed in $\mathrm{X}$. Now $\mathrm{f}$ is $\mathrm{a}^{*}$-closed and surjective implies $\mathrm{f}\left(\mathrm{f}^{-1}\left(\mathrm{~g}^{-1}(\mathrm{~V})\right)\right)=\mathrm{g}^{-1}(\mathrm{~V})$ is $\Lambda_{a}$-closed in $\mathrm{Y}$. Thus g is $\Lambda_{a}$-irresolute.

Remark 3.16 From the above results we have the following diagram where $\mathrm{A} \rightarrow \mathrm{B}$ represents $\mathrm{A}$ implies B but not conversely.

1.completely $\Lambda_{a}$-irresolute 2. almost a-continuous 3.airresolute 4.quasi $\Lambda_{a}$-irresolute 5. $\Lambda_{a}$-irresolute 6.strongly continuous

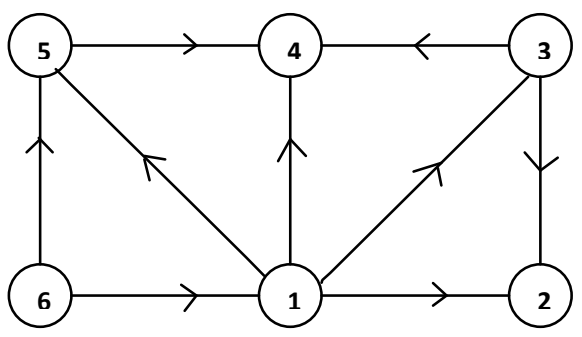

FIGURE : 1

\section{CHARACTERIZATIONS}

Lemma 4.1.[9] Let $S$ be an open subset of a topological space $(\mathrm{X}, \tau)$. Then the following hold:

(i) If $U$ is regular open in $X$, then so is $U \cap S$ in the subspace $\left(\mathrm{S}, \tau_{S}\right)$.

(ii) If $\mathrm{B} \subset \mathrm{S}$ is regular open in $\left(\mathrm{S}, \tau_{S}\right)$ there exists a regular open set $\mathrm{U}$ in $(\mathrm{X}, \tau)$ such that $\mathrm{B}=\mathrm{U} \cap \mathrm{S}$.

Theorem 4.2. If $\mathrm{f}:(\mathrm{X}, \tau) \rightarrow(\mathrm{Y}, \sigma)$ is completely $\Lambda_{a}$-irresolute and $\mathrm{A}$ is any open subset in $\mathrm{X}$, then the restriction $\left.\mathrm{f}\right|_{\mathrm{A}}: \mathrm{A} \rightarrow \mathrm{Y}$ is completely $\Lambda_{a}$-irresolute. 
Proof. Let $\mathrm{V}$ be any $\Lambda_{a}$-open subset of $\mathrm{Y}$. Since $\mathrm{f}$ is completely $\Lambda_{a}$-irresolute, $\mathrm{f}^{-1}(\mathrm{~V})$ is regular open in X. Since A is open in $\mathrm{X}$, by lemma 4.1 , ( $\left.\left.\mathrm{f}\right|_{\mathrm{A}}\right)^{-1}(\mathrm{~V})=\mathrm{A} \cap \mathrm{f}^{-1}(\mathrm{~V})$ is regular open in $\mathrm{A}$ and so $\left.\mathrm{f}\right|_{\mathrm{A}}$ is completely $\Lambda_{a}$-irresolute.

Lemma 4.3.[1] Let $Y$ be a preopen subset of a topological space $(\mathrm{X}, \tau)$. Then $\mathrm{Y} \cap \mathrm{U}$ is regular open in $\mathrm{Y}$ for every regular open subset $\mathrm{U}$ of $\mathrm{X}$.

Theorem 4.4. If $\mathrm{f}:(\mathrm{X}, \tau) \rightarrow(\mathrm{Y}, \sigma)$ is completely $\Lambda_{a}$-irresolute and $\mathrm{A}$ is any preopen subset of $\mathrm{X}$, then the restriction $\left.\mathrm{f}\right|_{\mathrm{A}}: \mathrm{A} \rightarrow \mathrm{Y}$ is completely $\Lambda_{a}$-irresolute.

Proof. Let $\mathrm{V}$ be any $\Lambda_{a}$-open subset of $\mathrm{Y}$. Since $\mathrm{f}$ is completely $\Lambda_{a}$-irresolute, $\mathrm{f}^{-1}(\mathrm{~V})$ is regular open in $\mathrm{X}$. Since $\mathrm{A}$ is preopen in $\mathrm{X}$, by lemma 4.3 , $\left(\left.\mathrm{f}\right|_{\mathrm{A}}\right)^{-1}(\mathrm{~V})=\mathrm{A} \cap \mathrm{f}^{-1}(\mathrm{~V})$ is regular open in $\mathrm{A}$ and so $\left.\mathrm{f}\right|_{\mathrm{A}}$ is completely $\Lambda_{a}$-irresolute.

Theorem 4.5. A topological space $(X, \tau)$ is connected if every completely $\Lambda_{a}$-irresolute function from a space $\mathrm{X}$ into any $\mathrm{T}_{0}$-space $\mathrm{Y}$ is constant

Proof. Suppose $\mathrm{X}$ is not connected and every completely $\Lambda_{a}$-irresolute function from a space $\mathrm{X}$ into $\mathrm{Y}$ is constant. Since $\mathrm{X}$ is not connected, there exists a proper nonempty clopen subset $\mathrm{A}$ of $\mathrm{X}$. Let $\mathrm{Y}=\{\mathrm{a}, \mathrm{b}\}$ and $\tau=\{\phi,\{\mathrm{a}\},\{\mathrm{b}\}, \mathrm{Y}\}$ be a topology for Y. Let $\mathrm{f}: \mathrm{X} \rightarrow \mathrm{Y}$ be a function such that $f(A)=\{a\}$ and $f(X-A)=\{b\}$. Then $f$ is a non-constant completely $\Lambda_{a}$-irresolute function such that $\mathrm{Y}$ is $\mathrm{T}_{0}$, a contradiction. Hence $\mathrm{X}$ must be connected.

Definition 4.6. A topological space $(X, \tau)$ is said to be

(i) $\Lambda_{a}$-connected [5] if $\mathrm{X}$ cannot be written as a disjoint union of two nonempty $\Lambda_{a}$-open subsets in $\mathrm{X}$.

(ii) $\mathrm{r}$-connected [10] if $\mathrm{X}$ cannot be written as a disjoint union of two nonempty regular open subsets in X.

(iii) hyperconnected [8] if every open subset of $\mathrm{X}$ is dense.

Theorem 4.7. If $\mathrm{f}:(\mathrm{X}, \tau) \rightarrow(\mathrm{Y}, \sigma)$ is completely $\Lambda_{a}$-irresolute surjection and $\mathrm{X}$ is r-connected, then $\mathrm{Y}$ is $\Lambda_{a}$ connected.

Proof. Suppose $\mathrm{Y}$ is not $\Lambda_{a}$-connected. Then $\mathrm{Y}=\mathrm{A} \cup \mathrm{B}$ where $\mathrm{A}$ and $\mathrm{B}$ are disjoint nonempty $\Lambda_{a}$-open subsets in $\mathrm{Y}$. Since $\mathrm{f}$ is completely $\Lambda_{a}$-irresolute surjection, $\mathrm{f}^{-1}(\mathrm{~A})$ and $\mathrm{f}^{-1}(B)$ are regular open sets in $X$ such that $X=f^{-1}(A) \cup$ $\mathrm{f}^{-1}(\mathrm{~B})$ and $\mathrm{f}^{-1}(\mathrm{~A}) \cap \mathrm{f}^{-1}(\mathrm{~B})=\phi$ which shows that $\mathrm{X}$ is not r-connected, a contradiction. Hence $\mathrm{Y}$ is $\Lambda_{a}$-connected.
Theorem 4.8. Completely $\Lambda_{a}$-connected images of hyperconnected spaces are $\Lambda_{a}$-connected.

Proof. Let $\mathrm{f}:(\mathrm{X}, \tau) \rightarrow(\mathrm{Y}, \sigma)$ be a completely $\Lambda_{a}$ irresolute function such that $\mathrm{X}$ is hyperconnected. Assume that B is a proper $\Lambda_{a}$-clopen subset of $Y$. Then $A=f^{-1}(B)$ is both regular open and regular closed set in $\mathrm{X}$ as $\mathrm{f}$ is completely $\Lambda_{a}$-irresolute. This clearly contradicts the fact that $\mathrm{X}$ is hyperconnected. Thus $\mathrm{Y}$ is $\Lambda_{a}$-connected.

Definition 4.9. A topological space $(X, \tau)$ is said to be

(i) $\Lambda_{a}-\mathrm{T}_{1}[6]$ if for every pair of distinct points $\mathrm{x}$ and $\mathrm{y}$,there exist $\Lambda_{a}$-open sets $\mathrm{G}$ and $\mathrm{H}$ containing $\mathrm{x}$ and $\mathrm{y}$ respectively such that $\mathrm{y} \notin \mathrm{U}$ and $\mathrm{x} \notin \mathrm{V}$.

(ii) $\Lambda_{a}-\mathrm{T}_{2}[6]$ if for every pair of distinct points $\mathrm{x}$ and $\mathrm{y}$,there exist disjoint $\Lambda_{a}$-open sets $\mathrm{G}$ and $\mathrm{H}$ containing $\mathrm{x}$ and $\mathrm{y}$ respectively .

(iii) $\mathrm{r}-\mathrm{T}_{1}[10]$ if for every pair of distinct points $\mathrm{x}$ and $\mathrm{y}$,there exist r-open sets $\mathrm{G}$ and $\mathrm{H}$ containing $\mathrm{x}$ and $\mathrm{y}$ respectively such that $\mathrm{x} \notin \mathrm{H}$ and $\mathrm{y} \notin \mathrm{G}$.

Theorem 4.10. If $\mathrm{f}:(\mathrm{X}, \tau) \rightarrow(\mathrm{Y}, \sigma)$ is completely $\Lambda_{a}$-irresolute injective function and $\mathrm{Y}$ is $\Lambda_{a}-\mathrm{T}_{1}$, then $\mathrm{X}$ is $\mathrm{r}$ $\mathrm{T}_{1}$.

Proof. Since $\mathrm{Y}$ is $\Lambda_{a}-\mathrm{T}_{1}$, for $\mathrm{x} \neq \mathrm{y}$ in $\mathrm{X}$, there exist $\Lambda_{a}$ open sets $V$ and $W$ such that $\mathrm{f}(\mathrm{x}) \in \mathrm{f}(\mathrm{y}) \in \mathrm{W}, \mathrm{f}(\mathrm{y}) \notin \mathrm{V}$, $\mathrm{f}(\mathrm{x}) \notin \mathrm{W}$. Since $\mathrm{f}$ is completely $\Lambda_{a}$-irresolute, $\mathrm{f}^{-1}(\mathrm{U})$ and $\mathrm{f}^{-1}(\mathrm{~V})$ are regular open sets in $\mathrm{X}$ such that $\mathrm{x} \in \mathrm{f}^{-1}(\mathrm{~V}), \mathrm{y} \in$ $\mathrm{f}^{-1}(\mathrm{~W}), \mathrm{x} \notin \mathrm{f}^{-1}(\mathrm{~W}), \mathrm{y} \notin \mathrm{f}^{-1}(\mathrm{~V})$. This shows that $X$ is $\mathrm{r}-\mathrm{T}_{1}$.

Theorem 4.11. If $\mathrm{f}:(\mathrm{X}, \tau) \rightarrow(\mathrm{Y}, \sigma)$ is completely $\Lambda_{a}$-irresolute injective function and $\mathrm{Y}$ is $\Lambda_{a}-\mathrm{T}_{2}$.then $\mathrm{X}$ is $\mathrm{T}_{2}$. Proof. Similar to the proof of theorem 4.10

Definition 4.12. A topological space $(X, \tau)$ is said to be

(i) $\Lambda_{a}$-compact [5], if every $\Lambda_{a}$-open cover of $\mathrm{X}$ has a finite subcover.

(ii) nearly compact[11], if every regular open cover of $\mathrm{X}$ has a finite subcover.

Theorem 4.13. If $\mathrm{f}:(\mathrm{X}, \tau) \rightarrow(\mathrm{Y}, \sigma)$ is completely $\Lambda_{a}$-irresolute surjective function and $\mathrm{X}$ is nearly compact, then $\mathrm{Y}$ is $\Lambda_{a}$-compact.

Proof. Let $\left\{V_{\alpha}: \alpha \in I\right\}$ be a cover of $\mathrm{Y}$ by $\Lambda_{a}$-open subsets of $\mathrm{X}$. Since f is completely $\Lambda_{a}$-irresolute, 
$\left\{\mathrm{f}^{-1}\left(V_{\alpha}\right): \alpha \in I\right\}$ is a regular open cover of $\mathrm{X}$. Since $\mathrm{X}$ is nearly compact, there exists a finite subset $\mathrm{I}_{0}$ of $\mathrm{I}$ such that $\mathrm{X}=$ $\cup\left\{\mathrm{f}^{-1}\left(V_{\alpha}\right): \alpha \in I_{0}\right\}$. Since $\mathrm{f} \quad$ is surjective, $\mathrm{Y}=$ $\cup\left\{V_{\alpha}: \alpha \in I_{0}\right\}$ and hence $\mathrm{Y}$ is $\Lambda_{a}$-compact.

Definition 4.14. A topological space $(X, \tau)$ is said to be $\Lambda_{a}$-normal [5], if each pair of disjoint closed sets can be separated by disjoint $\Lambda_{a}$-open sets.

Theorem 4.15. If $\mathrm{f}:(\mathrm{X}, \tau) \rightarrow(\mathrm{Y}, \sigma)$ is completely $\Lambda_{a}$-irresolute, closed injection and $\mathrm{Y}$ is $\Lambda_{a}$-normal ,then $\mathrm{X}$ is normal.

Proof. Let $\mathrm{E}$ and $\mathrm{F}$ be disjoint closed subsets of $\mathrm{X}$. Since $\mathrm{f}$ is closed, $f(E)$ and $f(F)$ are disjoint closed subsets of $Y$. Since $\mathrm{f}$ is $\Lambda_{a}$-normal, there exist disjoint $\Lambda_{a}$-open sets $\mathrm{U}$ and $\mathrm{V}$ such that $\mathrm{f}(\mathrm{E}) \subset \mathrm{U}$ and $\mathrm{f}(\mathrm{F}) \subset \mathrm{V}$. Since $\mathrm{f}$ is completely $\Lambda_{a}$ irresolute, $\mathrm{f}^{-1}(\mathrm{U})$ and $\mathrm{f}^{-1}(\mathrm{~V})$ are disjoint regular open subsets in $\mathrm{X}$ and hence open subsets in $\mathrm{X}$ such that $\mathrm{E} \subset \mathrm{f}^{-1}(\mathrm{U}), \mathrm{F}$ $\subset \mathrm{f}^{-1}(\mathrm{~V})$ which shows that $\mathrm{X}$ is normal.

Theorem 4.16. Let $f, g$ be functions. If $f$ and $g$ are completely $\Lambda_{a}$-irresolute functions and $\mathrm{Y}$ is a $\Lambda_{a}-\mathrm{T}_{2}$ space, then $\mathrm{P}=\{\mathrm{x} \in \mathrm{X}: \mathrm{f}(\mathrm{x})=\mathrm{g}(\mathrm{x})\}$ is $\delta$-closed.

Proof. Let $\mathrm{x} \notin \mathrm{P}$. We have $\mathrm{f}(\mathrm{x}) \neq \mathrm{g}(\mathrm{x})$. Since $\mathrm{Y}$ is $\Lambda_{a}$ $\mathrm{T}_{2}$, there exist disjoint $\Lambda_{a}$-open sets $\mathrm{A}$ and $\mathrm{B}$ in $\mathrm{Y}$ such that $\mathrm{f}(\mathrm{x}) \in \mathrm{A}$ and $\mathrm{g}(\mathrm{x}) \in \mathrm{B}$. Since $\mathrm{f}$ and $\mathrm{g}$ are completely $\Lambda_{a^{-}}$ irresolute, $f^{-1}(A)$ and $f^{-1}(B)$ are disjoint regular open subsets in $X$.Put $U=f^{-1}(A) \cap f^{-1}(B)$. Then $U$ is a regular open subset of $\mathrm{X}$ containing $\mathrm{x}$ and $\mathrm{U} \cap \mathrm{P}=\phi$ and hence $\mathrm{x} \notin$ $c l_{\delta}(A)$.Hence $\mathrm{P}$ is $\delta$-closed in $\mathrm{X}$.

\section{REFERENCES}

[1] Allam A.A. ; Zaharan A.M. ; Hasanein I.A. : On almost continuous, $\delta$-continuous and set connected mappings, Ind. J.Pure.Appl.Math ., 18(11),(1987),991-996.

[2] Crossley S.G. ; Hildebrand S.K. : Semitopological properties, Fund. Math., 74(1972), 233-254.

[3] Erdal Ekici : Some generalizations of almost contrasuper continuity, Filomat 21:2(2007),31-44.

[4] Levine N. : Strong continuity in topological spaces, Amer.Math.Monthly,67(1960),269.

[5] Lellis Thivagar M. ; Santhini C. : Another Form Of Weakly Closed Sets, Journal Of Ultra Scientist Of Physical Sciences -accepted for publication.

[6] Lellis Thivagar M. ; Santhini C. : New Generalization Of Topological Weak Continuity, Global Journal Of Mathematical Sciences : Theory and Practical -accepted for publication

[7] Erdal Ekici : On a-open sets, $\mathrm{A}^{*}$-sets and decompositions of continuity and super-continuity, Annales Univ. Sci. Budapest , 51(2008), 39-51.

[8] Erdal Ekici ; Saeid Jafari : On a Weaker Form of Complete Irresoluteness, Bol. Soc. Paran. Mat. 26, 1-2, (2008),81-87.

[9] Long P.E. ; Herrington L.L. : Basic properties Of regular-closed functions, Rend. Cir. Mat.Palermo, 27(1978), 20-28.

[10] Navalagi G.B. ; Abdullah M. ; Abdul Jabbar : Some remarks on completely $\alpha$-irresolute functions, International Journal Of Mathematical Sciences, Vol .5,No.1 (2006), 1-8.

[11] Singal M.K. ; Singal A. R. ; Mathur A. : On nearly compact spaces, Boll. UMI, 4(1969), 702-710. 